STATE RESEARCH CENTER OF RUSSIA

INSTITUTE FOR HIGH ENERGY PHYSICS

IHEP 2001-3

Yuri I. Arestov

\title{
TWIST-2 POLARIZED FRAGMENTATION FUNCTION IN THE OPEN CHARM PRODUCTION IN DIS
}

Talk given at Spin2000, Osaka, Japan, October 16-21, 2000

Protvino 2001 


\begin{abstract}
Arestov Yu.I. Twist-2 Polarized Fragmentation Function in the Open Charm Production in DIS : IHEP Preprint 2001-3. - Protvino, 2001. - p. 3, figs. 4.

To extract the polarized fragmentation function $G_{1}$, the transmitted polarization parameter $D_{L L}$ has been considered in the semi-inclusive leptoproduction process $e_{\uparrow}^{-}+p \rightarrow e^{-}+\Lambda_{c \uparrow}^{+}+X$ with both longitudinally polarized electron and charmed lambda. The polarization transfer $\hat{d}_{L L}$ for the lepton-gluon subprocess $e_{\uparrow}^{-}+g \rightarrow e^{-}+Q_{\uparrow} \bar{Q}$ was carefully studied, and it appeared to be sizable. The quantitative estimates of $\hat{d}_{L L}$ were made at the gluon momentum fraction $x_{g}=0.2$.
\end{abstract}

\title{
Аннотация
}

Арестов Ю.И. Поляризованная функция фрагментации твиста-2 в образовании открытого чарма в DIS.: Препринт ИФВЭ 2001-3. - Протвино, 2001. - 3 с., 4 рис.

Для определения поляризованной функции фрагментации $G_{1}$ твиста-2 рассматривается параметр переданной поляризации $D_{L L}$ в полуинклюзивном процессе $e_{\uparrow}^{-}+p \rightarrow e^{-}+\Lambda_{c \uparrow}^{+}+X$ с поляризовааными электронами и $\Lambda^{+}$. Детально изучена передача поляризации от $e_{\uparrow}^{-}$к тяжелому кварку в лептон-глюонном подпроцессе $e_{\uparrow}^{-}+g \rightarrow e^{-}+Q_{\uparrow} \bar{Q}$, где она оказывается значительной. Сделаны количественные оценки $\hat{d}_{L L}$ при импульсе глюона $x_{g}=0.2$.

(c) State Research Center of Russia Institute for High Energy Physics, 2001 
The polarized charmed lambda production is considered in SIDIS reaction

$$
e_{\uparrow}^{-}+p \rightarrow e^{-}+\Lambda_{c \uparrow}^{+}+X
$$

with the longitudinally polarized lepton beam shown in fig. 1 in the LO approximation. The polarization transmission parameter $D_{L L}$ is defined as

$$
D_{L L}=\frac{\sigma_{++}+\sigma_{--}-\sigma_{+-}-\sigma_{-+}}{\sigma_{++}+\sigma_{--}+\sigma_{+-}+\sigma_{-+}}
$$

where the subscripts $\{++\}$ etc. relate to the helicity states of the lepton and $\Lambda_{c}^{+}$.

In the absense of the initial polarization, $\Lambda_{c}^{+}$may be polarized only transversely to the production plane. A longitudinal component of the $\Lambda_{c}^{+}$polarization vector may arise due to the longitudinal lepton polarization in the initial state.

The polarization transmission coefficient which can be measured experimentally relates to the fragmentation function $G_{1}\left(z, \mu^{2}\right)(\mathrm{FF})$ through the following expression:

$$
D_{L L} \sim G\left(x_{g}\right) \cdot \hat{d}_{L L} \cdot G_{1}
$$

where $G\left(x_{g}\right)$ is the gluon distribution in the (unpolarized) proton and $\hat{d}_{L L}$ is the polarization transmission coefficient in the heavy quark pair production in the lepton-gluon scattering

$$
e_{\uparrow}^{-}+g \rightarrow e^{-}+Q_{\uparrow} \bar{Q} .
$$

In order to plan measurements of the unknown $\mathrm{FF} G_{1}$, it would be instructive to know the range of the values of $\hat{d}_{L L}$ in subprocess (4). The matrix element of reaction (4) incorporates the contributions of $u$-channel $(Q \bar{Q}$ configuration in Fig. 1), $t$-channel with the permuted Q's and the interference term. Below these contributions are referred to as $u u, t t$ and $t u$ terms.

As is seen from Fig. 2, the $d_{L L}$ properties may be quite different depending on $t$ or $u$-channel that is on the $Q \bar{Q}$ configuration in the diagram. The azimuthal angle $\phi$ counts from the lepton scattering plane. The total

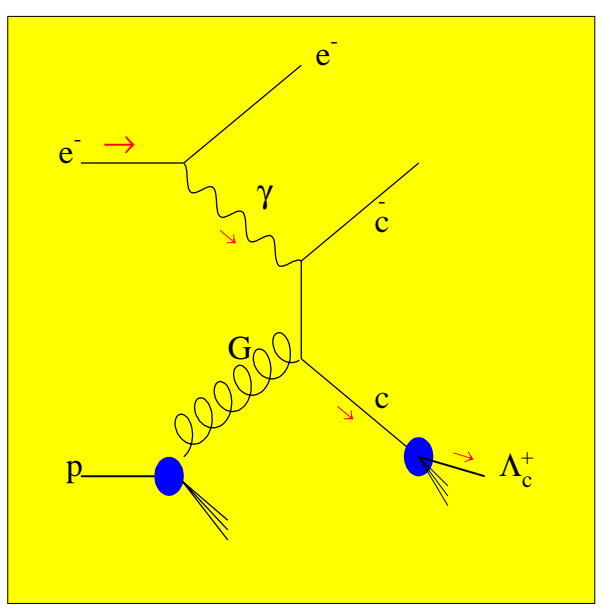

Fig. 1. The SIDIS reaction (1). 
$\phi$-dependence integrated over $p_{T}$ exhibits a remarkable behaviour with a deep minimum at $\phi=180^{\circ}$ and a positive maximum at $\phi=0^{0}\left(360^{\circ}\right)$. The maximum of the absolute value of $d_{L L}$ may reach 0.3 .

Apart from $p_{T}$ dependence it can be interesting to track down the $\hat{d}_{L L}$ dependence on $E_{Q}$, the quark energy, and on $\cos (Q, q)$, the cosine of the scattering angle in respect to the virtual photon direction. In Fig. 3 the corresponding two- and one-dimensional plots are shown in two regions: $\phi=0 \pm 30^{\circ}$ and $\phi=180 \pm 30^{\circ}$.

Finally, Fig. 4 presents the quark energy $E_{Q}$ dependence of the polarization coefficient $\hat{d}_{L L}$ integrated in separate hemispheres in respect to the virtual photon momentum. It is seen that at the reasonable values of the quark energy, the coefficient $\hat{d}_{L L}$ appears to be sizable.

From the above consideration, it follows that the model expectations for the fragmentation function $G_{1}$ (see (3)) may be quite reasonable because the underlying subprocess exhibits the large values of $\hat{d}_{L L}$ in some regions of the phase space.

Received January 19, 2001
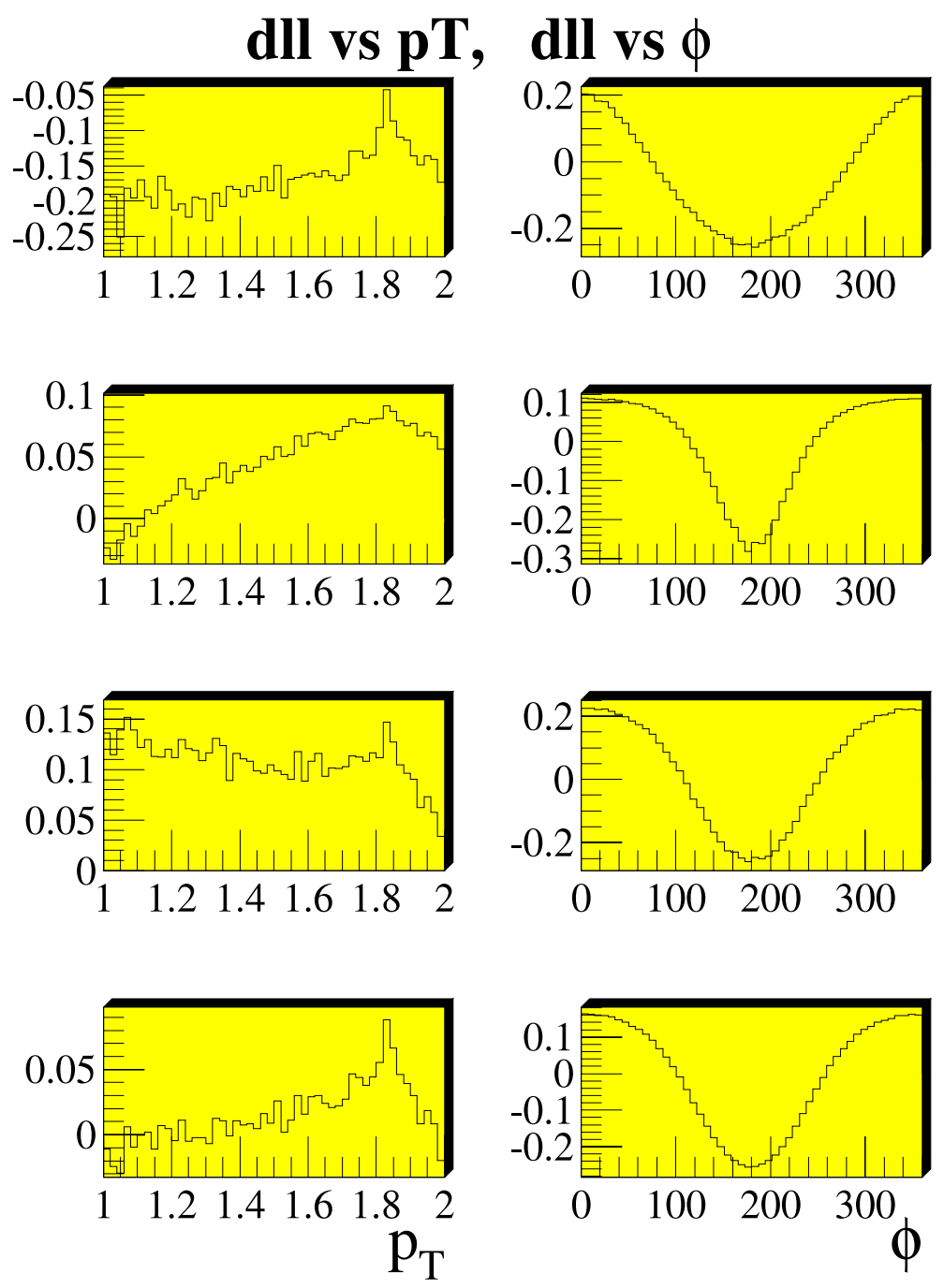

Fig. 2. $\hat{d}_{L L}$ versus $p_{T}$ and $\phi$ for (from up to down) $t t, u u, t u$ and total terms. 

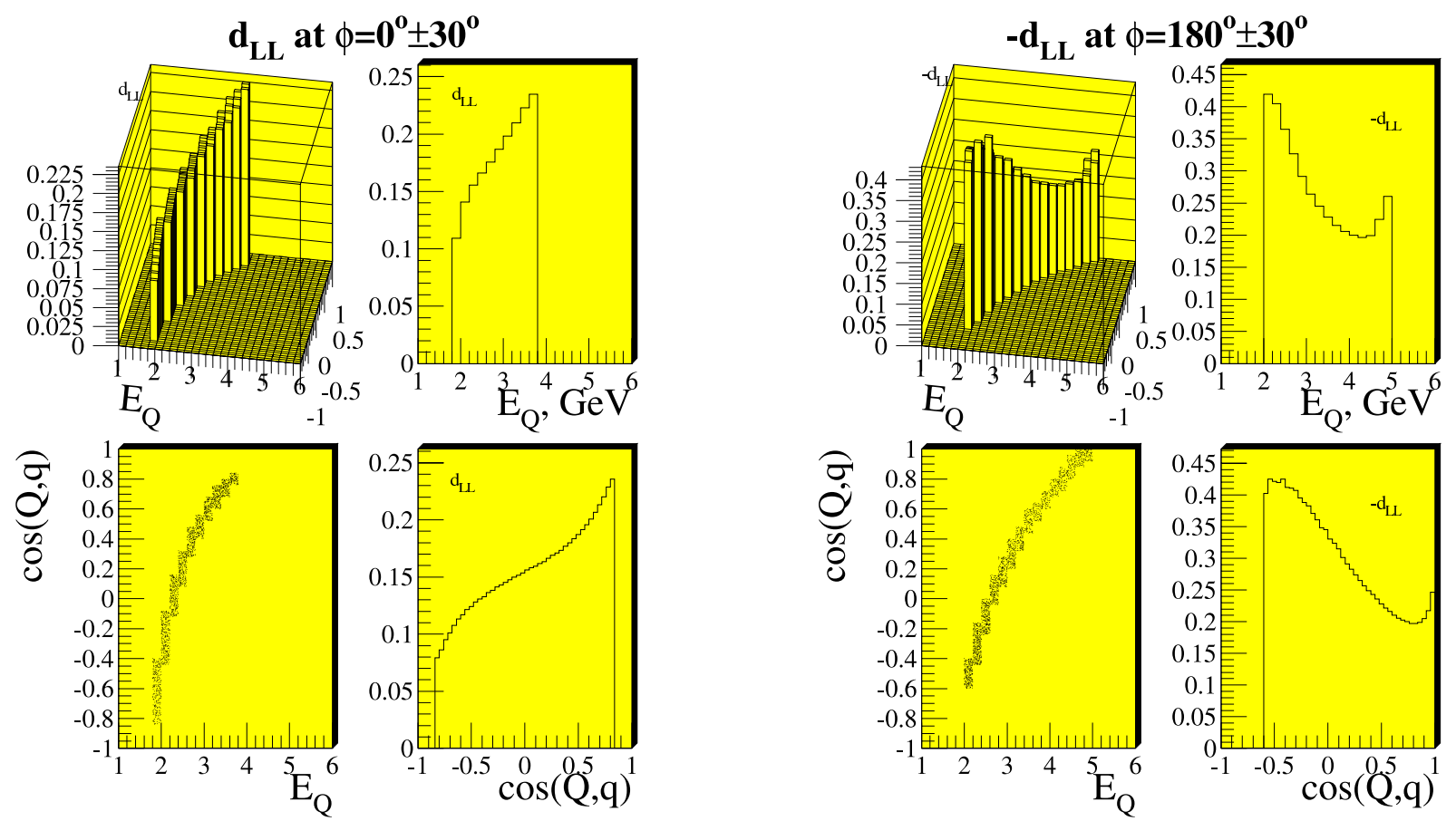

Fig. 3. $\hat{d}_{L L}$ dependence on the quark energy $E_{Q}$ and $(\mathrm{Q}, \mathrm{q})$ angle (see the text).

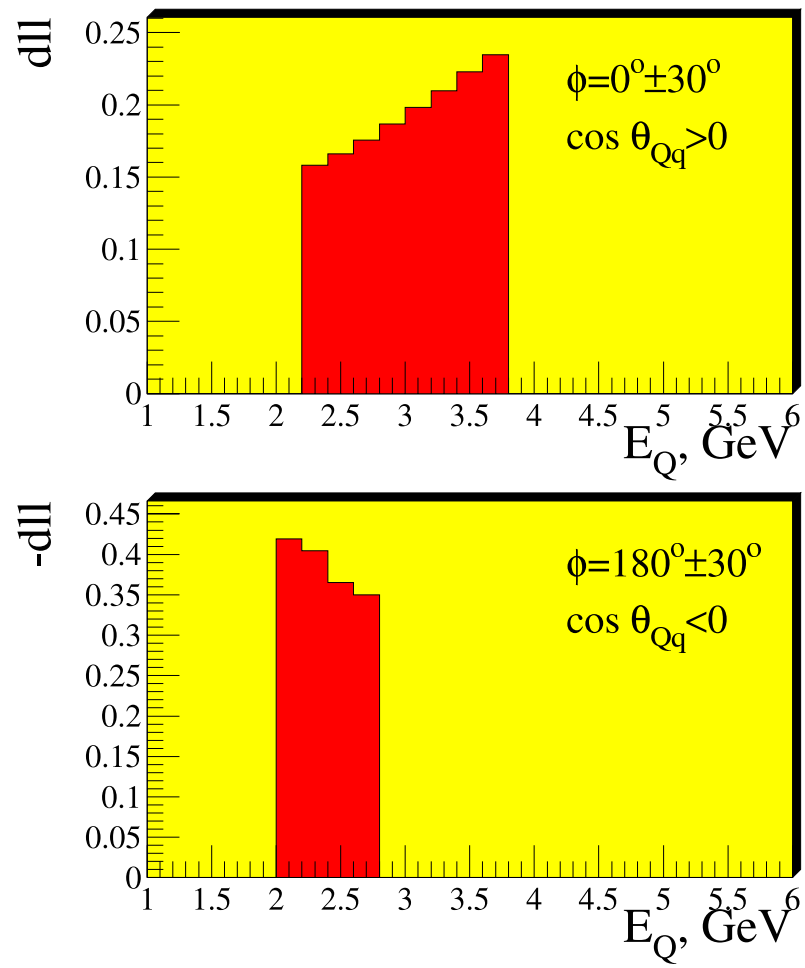

Fig. 4. The quark energy dependence of $\hat{d}_{L L}$ in the forward and backward hemispheres. 
Ю.И.Арестов

Поляризованная функция фрагментации твиста-2 в образовании открытого чарма в DIS.

Оригинал-макет подготовлен с помощью системы $\mathrm{IAT}_{\mathrm{E}} \mathrm{X}$.

Редактор Е.Н.Горина.

Подписано к печати 29.01.2001. Формат $60 \times 84 / 8$. Офсетная печать.

Печ.л. 0.37. Уч.-изд.л. 0.3. Тираж 160. Заказ 50. Индекс 3649.

ЛР №020498 17.04.97.

ГНЦ РФ Институт физики высоких энергий

142284, Протвино Московской обл. 
Индекс 3649

П Р Е П Р И Н Т 2001-3, И В Э, 2001

